\title{
Nurse to adolescent health communication process: approach to Event History Calendar
}

\author{
Processo de comunicação em saúde da enfermagem com o adolescente: abordagem do Event History Calendar \\ El proceso de comunicación en salud de la enfermería con el adolescente: un enfoque desde el Event History Calendar
}

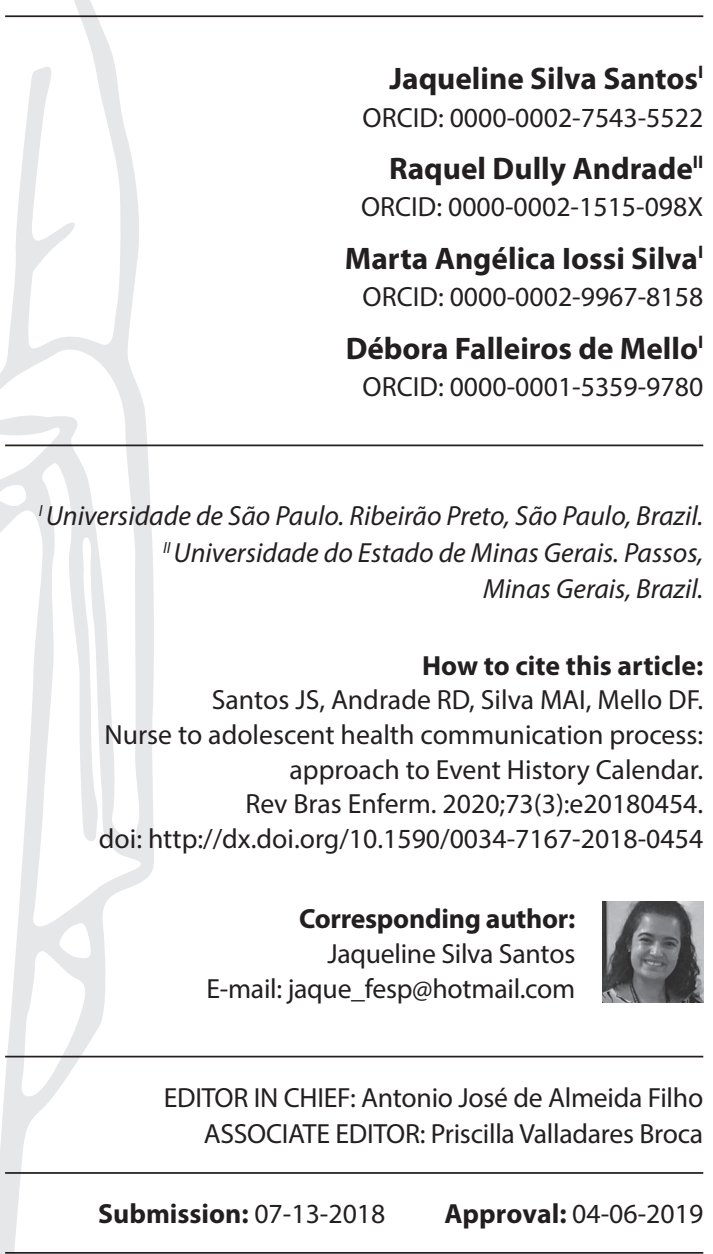

\begin{abstract}
Objectives: comprehend the Event History Calendar components that are relevant for the nurse to adolescent communicative process, in the context of Primary Health Care. Methods: reflective study, based on the Event History Calendar approach, in the relational, communicative, and educational dimensions. Results: best practices for adolescent health promotion are vital and constitute a challenge to nurses. The Event History Calendar is a potential tool for research and care practices to comprehend the needs of adolescents, with reminder of key personal events, culturally and socially specific. The comprehension of retrospective data referring to activities, behaviors, experiences and transitions of life, in certain periods of time, enables dialogue and new understandings about the history of adolescents. Final Considerations: the Event History Calendar provides nursing professionals with an expansion of their practice in educational, relational, and communicative dimensions, as well as to instruct care planning and management.
\end{abstract}

Descriptors: Health Communication; Nursing; Adolescent; Health Promotion; Public Health Nursing.

\section{RESUMO}

Objetivos: apreender os componentes do calendário histórico de eventos relevantes ao processo comunicativo do enfermeiro com o adolescente, no âmbito da Atenção Primária à Saúde. Métodos: estudo reflexivo, fundamentado na abordagem do Event History Calendar, nas dimensões relacionais, comunicativas e educativas. Resultados: boas práticas para a promoção da saúde dos adolescentes são vitais e configuram um desafio para o enfermeiro. O Event History Calendar é ferramenta potencial para pesquisas e práticas de cuidado para apreender necessidades do adolescente, com recordatório de eventos-chave pessoais, culturalmente e socialmente específicos. A apreensão de dados retrospectivos referentes a atividades, comportamentos, experiências e transições da vida, em determinados períodos de tempo, possibilita o diálogo e novos entendimentos sobre a trajetória do adolescente. Considerações Finais: 0 Event History Calendar confere ao profissional enfermeiro uma expansão de sua atuação em dimensões educativas, relacionais e comunicativas, bem como para instruir planos e gestão do cuidado.

Descritores: Comunicação em Saúde; Enfermagem; Adolescente; Promoção da Saúde; Enfermagem em Saúde Pública.

\section{RESUMEN}

Objetivos: comprender los elementos del calendario histórico de eventos relevantes al proceso comunicativo del enfermero con el adolescente, en elámbito de la Atención Primaria de Salud. Métodos: estudio reflexivo, desde el enfoque del Event History Calendar, en las dimensiones relacionales, comunicativas y educativas. Resultados: las buenas prácticas para la promoción de la salud de los adolescentes son esenciales y constituyen un desafío al enfermero. El Event History Calendar es una herramienta potencial a las investigaciones y prácticas de asistencia para comprender las necesidades de los adolescentes, y contiene un recordatorio de los eventos clave personales, culturales y sociales específicos. El conocimiento de los datos retrospectivos referentes a las actividades, los comportamientos, las experiencias y el paso de la vida, en ciertos períodos de tiempo, permite el diálogo y nuevos entendimientos sobre la trayectoria del adolescente. Consideraciones Finales: el Event History Calendar permite que el profesional enfermero aumente su actuación en las dimensiones educativas, relacionales y comunicativas, además de establecer planes y una gestión del cuidado.

Descriptores: Comunicación en Salud; Enfermería; Adolescente; Promoción de la Salud; Enfermería en Salud Pública. 


\section{INTRODUCTION}

Adolescents, developing subjects, are part of a specific social, political, economic and cultural context, showing vulnerabilities and potentials that must be considered in initiatives for this segment. Health practices must consider the peculiarities and needs of each adolescent and, to this end, the construction of spaces that allow horizontal dialogue emerges as essential for the health promoting approach, which stimulates protagonism in adolescence ${ }^{(1-2)}$.

Communication can be understood as a work instrument of health professionals, since it intermediates encounters and contributes to the establishment of relationships between professionals and subjects ${ }^{(3)}$. In the context of Primary Health Care (PHC), nurses have relevant roles for coordination and mediation, performing diverse activities inherent to the care process and to care management, meeting the health needs of individuals. Considering the different needs of adolescents, it is emphasized the importance of implementing dialogic communication, based on horizontal relations, with respect to culture and knowledge sharing ${ }^{(1,3-4)}$.

In adolescent health care, nurses may come across gaps, often related to weak bonds and little adherence to health activities, with best practices being essential in the care process as central in Nursing.

Aspects and contexts that provide the comprehension of health needs or situations require constant expansion of understanding relevant to the care process. Accordingly, retrospective data collection can support the professional practice of nurses for the reconstruction of important health-related events ${ }^{(5)}$. Retrospective memory constitutes a challenge and the mapping of key events can provide researchers and nursing professionals with a rich and comprehensive method to investigate and analyze health contexts ${ }^{(5)}$.

In order to contribute to the expansion of adolescent health care, which supports the principle of completeness in health care, this study brings reflections on the Event History Calendar (EHC) (6) approach, to shed light on researches and care practices with potential to comprehend the needs of adolescents and contribute to promote their complete development.

\section{OBJECTIVES}

To comprehend the Event History Calendar components that are relevant for the nurse to adolescent communicative process, in the context of Primary Health Care.

\section{Adolescent health care in the context of Primary Health Care}

Adolescence is defined as a period of intense individual and relational transformations, which are essential in the human beings' development process ${ }^{(1)}$. Adolescents are faced with unique experiences, which allow the reconstruction of relations and closer bonds of friendship and partnership, being a step in which the subject finds himself in a setting imbued with changes and challenges imposed by the context experienced ${ }^{(1)}$.

Adolescence cannot be delimited only using chronological criteria, because it also involves physical, social and cultural aspects ${ }^{(1)}$, to be considered in the health professionals' care for that segment. Adolescent health involves recognizing the influence of a multiplicity of factors on the adolescent development process, which may relate, for example, to the exercise of rights, family experiences, friendships, inclusion in the school context, aspirations and constructions of future projects.

The activities and policies aimed at the adolescent segment should consider the different individual, social and cultural characteristics of this population ${ }^{(1)}$. Therefore, in care, health care professionals need to understand how each adolescent experiences the peculiar events of this phase of development, as well as their knowledge, skills and beliefs relating to health ${ }^{(1)}$. Health programs, laws, and policies can contribute to a qualified approach to adolescents ${ }^{(2)}$. Clinical practice in the context of PHC is characterized by closeness and bond with subjects, families and community, with potential for the nursing professionals' practice, consistently with the reality and needs encountered.

Thus, it is important that nursing professionals have skills and adopt best practices in the adolescent care process, with awareness extended to the various social determinants involved in the health-disease process and in the work in PHC from the perspective of intersectoral approach and completeness of adolescent care.

\section{The communicative process for adolescent health promotion}

Adolescent health promotion enables the improvement of their life and health conditions ${ }^{(2)}$. Considering the close association between communication and health promotion, it is highlighted here the importance of establishing effective communicative process with adolescents. Health promotion is understood as a dynamic area, which needs to respond to constant challenges ${ }^{(2)}$ that arise in accordance with the context in which people live.

Based on the understanding that healthy development in adolescence is associated with a multitude of physical, psychological, social, and environmental factors ${ }^{(1)}$, and that, in addition to ensuring the survival of adolescents, it is necessary to provide a care that is not aimed only at organic demands, but that considers the context of the adolescent development process ${ }^{(1)}$, adolescent health promotion is vital and constitutes a challenge for PHC nurses.

In these circumstances, it is important that nurses foster the contextualization and problematization of the reality experienced by adolescents $s^{(7)}$. Through sensitive listening, nurses can observe vulnerabilities and adversity, and develop actions aimed at strengthening the adolescents' protagonism and resilience, seeking to strengthen health promotion ${ }^{(7)}$. Accordingly, there is a need to review established conceptions of adolescence as being a difficult phase, which can hinder the establishment of relations between nurses and adolescents and hinder the formation of a bond of trust and the construction of integral care.

Thus, approaches that enable subjects to speak about their experiences and professionals to listen in a sensitive manner have been highlighted in adolescent health care, as they allow for questions, discussions and reflections, contributing to critical thinking and construction of new meanings ${ }^{(4)}$. Another relevant aspect is the nurses' communication skills, with use of appropriate language, posture adopted, knowledge of strategies that can 
facilitate the approach and dynamics that are culturally consistent with the needs of adolescents ${ }^{(2)}$, avoiding attitudes and postures that are imposed and out of context.

Therefore, the communicative act can enable the therapeutic relationship of sharing and help and lead to the conditions for transforming health promotion actions, in which the subjects' autonomy and protagonism are strengthened, thus contributing to more humanized and participatory practices ${ }^{(3)}$.

Reflecting on new modes of adolescent care, dissociated from normative and prescriptive actions, it is observed the potential for approaches that enable humane care, negotiation and bond creation, using active teaching-learning methodology, such as rounds of conversation, which can function as a strategy to foster the emancipation of subjects ${ }^{(4)}$.

Adolescents can be protagonists in health actions and, seeking the involvement and empowerment of adolescents, nurses may also foster education among peers, in which adolescents, after being trained, act as multipliers of knowledge with other adolescents, which may foster health promotion ${ }^{(2)}$.

Working in different settings can also be favorable to promoting adolescent health. Art/education, for example, which presents as a critical-reflective strategy, can be an advantageous space for the activity of nurses ${ }^{(7)}$. To that end, it is necessary to trace, in the registered community, artistic experience spaces and coordinate with health actions, aiming at interdisciplinary work ${ }^{(7)}$. Participatory communication during adolescent care should be encouraged, as it may contribute to the empowerment of these subjects ${ }^{(2)}$.

In reflecting on the adolescent development process and on the establishment of communication with adolescents, geographical and regional diversity should also be considered ${ }^{(1)}$. It is worth noting that, for the promotion of health in adolescence, social and family contexts emerge as essential ${ }^{(7)}$. Thus, in care practices, nurses should consider the influences of the adolescents' culture and relationship network.

In care activities, nurses should seek to understand the adolescents' discourse and life context, in addition to creating spaces for sharing experiences. Thinking on the establishment of the communicative process aimed at the needs of adolescents, nurses can use certain tools and, in this study, it is highlighted the Event History Calendar (EHC).

\section{The Event History Calendar as a tool for adolescent care}

The peculiarities of each adolescent and the potential for effective communication need to be considered for the promotion of health. In this context, the nurses' use of tools that enable dialogue with adolescents is crucial, such as the Event History Calendar $(E H C)$, which deals with different aspects of the history of life ${ }^{(6)}$.

Mapping key events constitutes a method that uses a process of recovery of a specific period of time or date, setting up a calendar to assist an individual to recall relevant personal episodes and events, locations, culturally and socially specific ${ }^{(5)}$.

The EHC has been disseminated in international studies ${ }^{(6,8-10)}$, presented as a tool that can be used by nurses to collect retrospective data relating to events, activities, behaviors, experiences, and transitions of the life of subjects, occurred in certain periods of time ${ }^{(6)}$. The EHC design is structured in columns and rows and is determined in accordance with the objectives and the information to be collected, showing in the columns indications of time (day, week, month, year) and in the rows the domains of the subject's life (behaviors, activities, or events) ${ }^{(6)}$. Figure 1 presents an example of EHC used in a research on adolescent risk behavior, conducted with girls aged 15 to 19 years ${ }^{(6)}$.

ID\#:_Ethnicity:__Birthdate:__Interview Date:__Interview\#:__ Interview Time:__Edit Time:__ Interviewer:

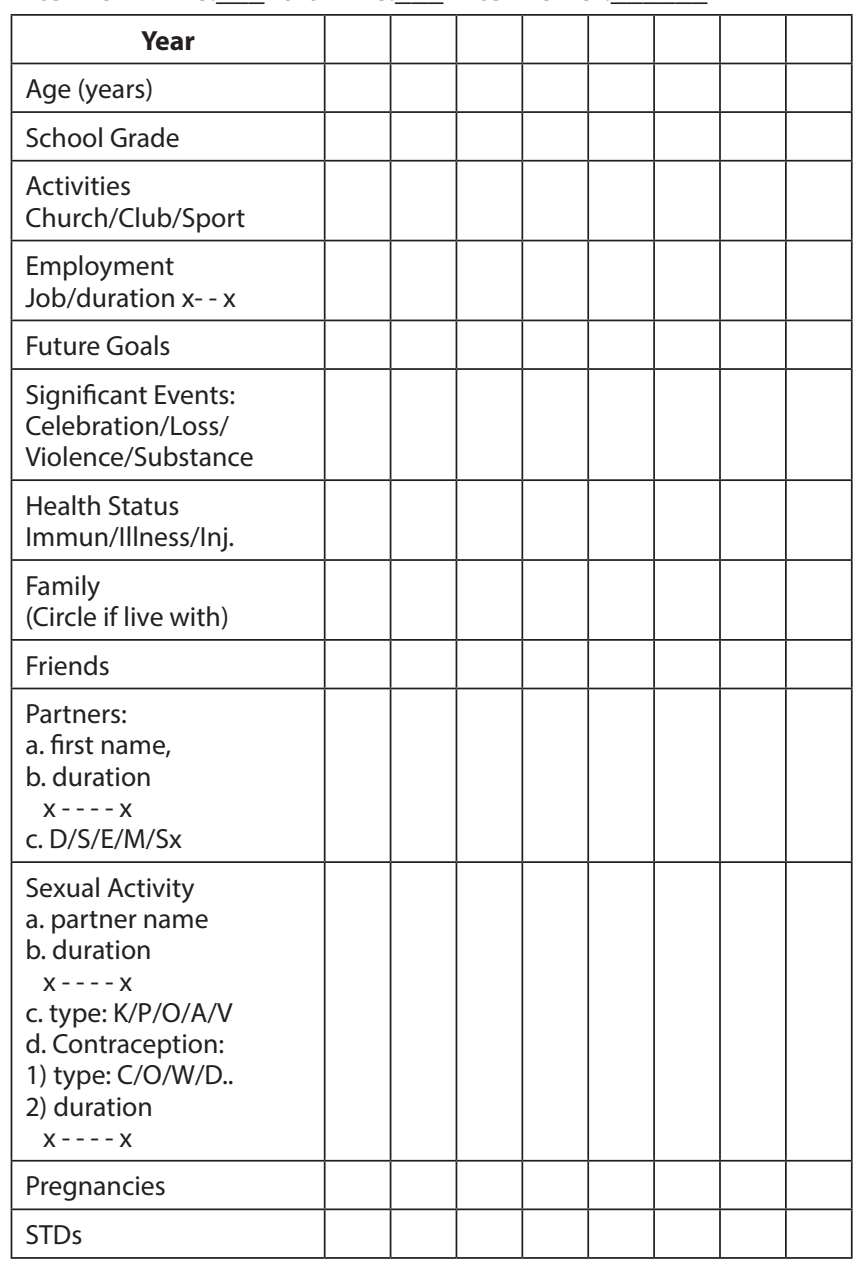

Figure 1 - Scheme of the Event History Calendar - Adolescent health risk behavior $^{(6)}$

Despite being a structured tool, the EHC allows flexibility, stimulates the remembrance of past events ${ }^{(6)}$, and promotes communication ${ }^{(8)}$. The EHC, therefore, is aimed at a precise and comprehensive reconstruction of successive events of the adolescent's life, providing information as to the time, the occurrence, and the sequence of events ${ }^{(6)}$.

When the EHC is used, completion by adolescents and later review ${ }^{(9)}$ and discussion ${ }^{(8)}$ with nurses may be encouraged. In the field of PHC, in health care services and programs, the EHC may be completed by adolescents while waiting for service in the waiting room, for example, and discussed with nurses during nursing consultation. In other situations of adolescent care, preliminary to service, it is important that nurses analyze the completed EHC, to trace the behaviors and/or vulnerable situations, sources of protection, settings, key people and other relevant issues to be addressed in the nursing consultation ${ }^{(10)}$. 
It is important to stress that it is essential that, before the first completion, nurses should present the tool to adolescents, explain its purpose, recognize the adolescents' interests in using it, and clarify any doubts. Another possibility is to apply it during the nursing consultation. In both situations, the EHC may function as a trigger for the establishment of communicative process between nurses and adolescents.

In each instance of service in the health unit, adolescents fill in a timeline column of the EHC, which enables the mapping of a sequence of events. After completion of the EHC by the adolescent, the health professional may adapt the communication according to the answers contained in the tool ${ }^{(8)}$. This process can assist in observing aspects relating to considerations of perspectives and contexts experienced by the subjects, as well as in the survey and understanding of their needs ${ }^{(8)}$.

In addition, there is a study ${ }^{(10)}$ that suggests ease in integrating the EHC approach to adolescent care in health service, and the non-occurrence of negative impact on the number of service instances. Accordingly, use of the EHC has potential for improving the quality of adolescent care and health care management.

By using the EHC, nurses enable adolescents to view, over time, their behavioral patterns ${ }^{(10)}$. Viewing the completed EHC provides adolescents with opportunities to understand experienced moments and life paths ${ }^{(8)}$. In addition, individuals may reveal confidential information when reflecting on their life paths with the completion of the $\mathrm{EHC}^{(8)}$, which suggests contributions to the tracing of demands of care by the nurse. Thus, the EHC has potential to assist in recalling and reporting behaviors in different dimensions, physiological patterns, adherence to treatment, and symptom management ${ }^{(6)}$. A study indicates that, to adolescents, the $\mathrm{EHC}$ may also be seen as a tool that promotes the addressing of complex issues, such as those related to sexuality, in a more open and detailed manner ${ }^{(10)}$.

Therefore, the EHC approach can foster interactions, discussions and shared understandings, with recognition of the perception of adolescents ${ }^{(8)}$ and joint development of health promotion strategies $^{(10)}$. Accordingly, the EHC has much potential for nursing care in comprehensive adolescent health care, with contributions to the clinical practice of nurses in PHC.

The development of the EHC with adolescents is associated with health promotion ${ }^{(9-10)}$, with focus on the establishment of horizontal communication and in accordance with the singularities of each adolescent. A study ${ }^{(9)}$ pointed out the contributions of the EHC to communication and the improvement in sexual risk assessment for female adolescents. The EHC approach also provides benefits to the adolescents' communication, involvement and awareness as to the events of their lives ${ }^{(10)}$.
Therefore, in times of health care, it is comprehended that the practice of nurses is enriching when assuming a posture of openness to the demands and perceptions of adolescents, which may contribute to the bond ${ }^{(8)}$ and partnership relations ${ }^{(10)}$ in favor of integral health care. In this sense, the use of care tools, such as the EHC, which enables that life contexts are considered and discussed in health care service, may contribute to the effectiveness of the communicative process and have positive impact on integral adolescent care ${ }^{(8)}$.

In adolescent care, the use of dialogic communication by nurses may foster the understanding of situations experienced, the creation and strengthening of bonds, as well as the promotion of autonomy and self care. The understanding of the uniqueness of being an adolescent ${ }^{(1)}$, of the importance of promoting the empowerment and autonomy of the subject point to the need for innovative strategies, with emphasis on the potential of the EHC as a tool of care.

Thus, the EHC has been seen as a suitable tool for adolescent care, allowing the survey and collection retrospective information, stimulating discussion and understanding of behaviors and emotions of the subject ${ }^{(6)}$, being efficient in terms of time and clinical usefulness ${ }^{(9)}$, with positive impacts on the communication with adolescents ${ }^{(10)}$, contributing to the expanded understanding of certain attitudes of adolescents, which may be related to past events.

\section{FINAL CONSIDERATIONS}

The comprehension of retrospective data referring to activities, behaviors, experiences and transitions of life, occurred in certain periods of time, enables dialogue and new understandings about the experiences of adolescents.

The EHC, recognized as part of the best practices in health, provides nursing professionals with an expansion of their work with adolescents, in educational, relational, and communicative dimensions, as well as to instruct care planning and management.

The nurse to adolescent communicative process can be fostered through the use of approaches that favor dialogue and allow the recognition of the plurality of events and contexts of adolescence. This reflective study suggests the need for future research that explores the use of the EHC in contextualized situations, the domains of the tool, and the use by health professionals, in different settings and situations of the path in adolescence.

\section{FUNDING}

Study associated with research project funded by the National Council for Scientific and Technological Development (CNPq), process no. 309085/2015-2.

\section{REFERENCES}

1. Senna SRCM, Dessen MA. Reflexões sobre a saúde do adolescente brasileiro. Psicol Saude Doenças. 2015;16(2):217-29. doi: 10.15309/15psd160208.

2. Silva KVLG, Gonçalves GAA, Santos SB, Machado MFAS, Rebouças CBA, Silva VM, et al. Training of adolescent multipliers from the perspective of health promotion core competencies. Rev Bras Enferm. 2018;71(1):89-96. doi: 10.1590/0034-7167-2016-0532.

3. Coriolano-Marinus MWL, Queiroga BAM, Ruiz-Moreno L, Lima LS. Comunicação nas práticas em saúde: revisão integrativa da literatura. 
Saude Soc. 2014;23(4):1356-69. doi: 10.1590/S0104-12902014000400019.

4. Sampaio J, Santos GC, Agostini M, Salvador AS. Limites e potencialidades das rodas de conversa no cuidado em saúde: uma experiência com jovens no sertão pernambucano. Interface (Botucatu). 2014;18(suppl 2):1299-311. doi: 10.1590/1807-57622013.0264.

5. Carter-Harris L. An introduction to key event mapping: a primer for nurse researchers. Appl Nurs Res. 2015;28(2):83-5. doi: 10.1016/j. apnr.2015.01.003.

6. Martyn KK, Belli RF. Retrospective data collection using event history calendars. Nurs Res. 2002;51(4):270-4. doi: 10.1097/00006199-200207000-00008.

7. Farre AGMC, Pinheiro PNC, Vieira NFC, Gubert FA, Alves MDS, Monteiro EMLM. Adolescent health promotion based on community-centered arts education. Rev Bras Enferm. 2018;71(1):26-33. doi: 10.1590/0034-7167-2016-0078.

8. Martyn KK, Munro ML, Darling-Fisher CS, Ronis DL, Villarruel AM, Pardee M, et al. Patient-centered communication and health assessment with youth. Nurs Res. 2013;62(6):383-93. doi: 10.1097/NNR.0000000000000005.

9. Martyn KK, Reifsnider E, Murray A. Improving adolescent sexual risk assessment with event history calendars: a feasibility study. J Pediatr Health Care. 2006;20(1):19-26. doi: 10.1016/j.pedhc.2005.07.013.

10. Martyn KK, Darling-Fisher C, Pardee M, Ronis DL, Felicetti IL, Saftner MA. Improving sexual risk communication with adolescents using event history calendars. J Sch Nurs. 2012;28(2):108-15. doi: 10.1177/1059840511426577. 